\title{
ENSINO DE MATEMÁTICA: LUZ NO TÚNEL
}

\section{Metodologia para o ensino de Matemática apóia-se na experiência do cotidiano para introduzir conceitos, facilitando a compreensão do aluno}

No início deste ano letivo, devido ao processo de municipalização sofrido em minha cidade, fiquei agregada (adida) a uma escola na cidade vizinha. Em princípio senti que essa era a pior escola em que havia trabalhado ao longo de meus dez anos de magistério: o pior prédio (algumas salas funcionam em contêiner), a comunidade com muitos problemas e a clientela apresentando uma série de deficiências e carências. Alunos rotulados, analfabetos, agressivos, indisciplinados etc. A partir desta constatação, senti necessidade de dedicar-me mais do que estava acostumada. Analisar a situação sob esta perspectiva levou-me a perceber que o problema não era só de aprendizagem, e sim de ensino, postura e metodologia do profissional envolvido.

Senti a necessidade de procurar maneiras alternativas de lecionar, pois uma lista de contas na lousa para quem mal sabe escrever o seu próprio nome era algo inviável. Comecei dispensando o livro didático e acolhendo os livros Atividades de Matemática/CENP, dirigidos às segundas, terceiras e quartas séries, para atender às diferentes necessidades das salas em que leciono. Aos poucos fui conseguindo progresso com alguns alunos. Em boa hora surgiu o Programa de Educação Continuada da Secretaria Estadual de Ensino de São Paulo (PEC/SEESP) de Matemática, na Pontifícia Universidade Católica de São Paulo (PUC-SP), que me mostrou novos conceitos, valores e metodologias de trabalho no ensino de Matemática.

Para alguns alunos o ensino livresco, sistematizado, quantitativo, dando muita importância ao conteúdo, não funcionou. Agora utilizo o conhecimento de meus alunos e a partir dele desenvolvo as aulas de Matemática, tornando-as mais próximas do dia-a-dia desses alunos, de forma que, até aqueles que mal lêem e escrevem, sejam capazes de resolver os problemas e os exercícios propostos, o que antes nem mesmo tentavam.

Essa clientela, que considerei a pior no início do ano, fez com que eu passasse a valorizar meu trabalho e os resultados obtidos com ela a ponto de me inscrever no concurso do MEC Prêmio Incentivo à Educação Fundamental, fato

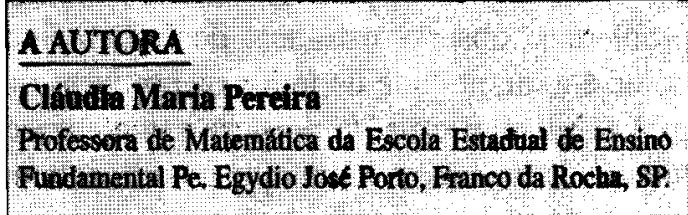


que antes nunca havia me interessado. A partir de então sinto-me digna de participar, pois tão grande quanto a simplicidade da experiência é a satisfação que tive de compartilhá-la com meus alunos; sinto como se tivesse tirado água mineral de um poço aparentemente seco.

O planejamento das atividades desenvolvidas nortearam-se pelos seguintes objetivos: experimentar na sala de aula uma nova forma de lecionar; usar e respeitar o conhecimento dos alunos em sala de aula; valorizar a atuação dos alunos e a auto-estima; aproximar a Matemática escolar da matemática da vida do aluno; fazer com que os alunos não aceitem alguns conceitos como verdadeiros sem antes testá-los e questioná-los; mostrar aos alunos que temos diversas maneiras de resolver um mesmo problema; fazer com que os alunos busquem essas maneiras; desenvolver a idéia de que medir significa comparar grandezas de mesma natureza; levar o aluno a perceber a necessidade de uma unidade de padrão de medida, como uma convenção que facilita a comunicação; e levá-lo a fazer estimativas de medida.

\section{DESENVOLVIMENTO DO PROJETO}

A experiência teve início com uma atividade sugerida no PEC: a partir de um folheto de supermercado os alunos deveriam fazer uma listagem de produtos, preços e quantidades para que posteriormente fizéssemos simulações de compra. Trabalhamos cálculo aproximado, estimativa, cálculo mental, compras com a calculadora, sistema monetário, formas de pagamento etc.

Percebi que não sabiam o significado e a representatividade das siglas das medidas de capacidade e peso. Pedi para que na próxima aula trouxessem medidores - objetos utilizados para medir geralmente líquidos, que têm riscos e números mostrando a quantidade de líquido. Os materiais utilizados foram: folheto de supermercado, água, diferentes medidores de diversas formas e tamanhos e calculadora.

Como recursos para a resolução dos exercícios e problemas foram utilizados cálculo mental, cálculo sistematizado, calculadora, medidores.

A primeira atividade desenvolveu-se a partir da observação do folheto de supermercado. Os objetivos específicos foram os de fazer o aluno reconhecer e distinguir medidas de capacidade e peso; e reconhecer os produtos ilustrados ou descritos que podem ser medidos pela sua capacidade.

Utilizei como procedimento a leitura do enunciado do seguinte problema: "observe o folheto de supermercado, desenhe e coloque o nome e a quantidade de todos os produtos que tiverem as siglas 1 , It e ml". (Utilizei a sigla $l t$, pois era a que aparecia no folheto como abreviatura de litro e expliquei que a nomenclatura correta é l.) 


\section{Gráfico A - Demonstrativo da execução da primeira atividade}

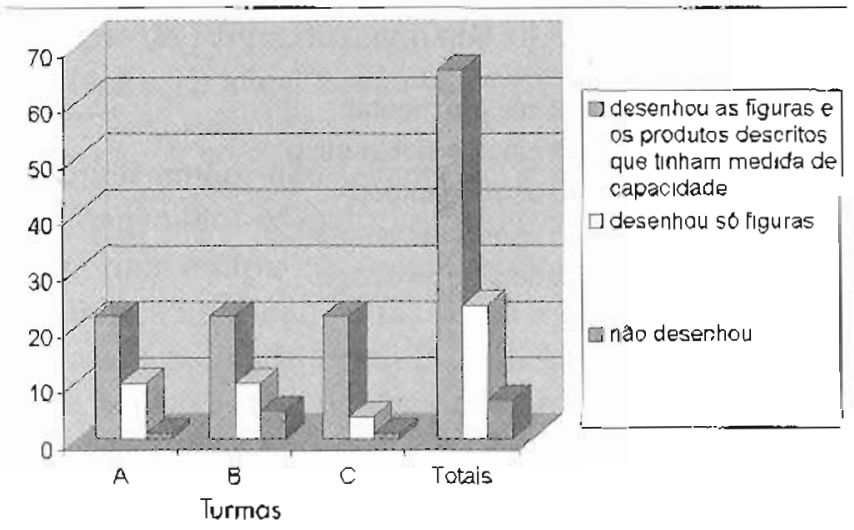

Ao final da atividade veriliquei que a maioria dos alunos conseguiu cumprir parcialmente os objetivos propostos. Todos que realizaram a atividade desenharam somente os produlos medidos pela capacidade. Alguns alunos somente desenharam o que estava em forma gráfica no folhelo. Poucos alunos, apesar de desenharem todos os produtos, deixaram de colocar a capacidade de cada um.

A segunda alividade teve como objetivo específico fazer com que os alunos reconhecessem os produtos menores que 1 litro; associassem e relacionassem litro com seus submúltiplos mais usados; trabalhassem campos conceituais aditivos.

Para alcançar esses objetivos adotei como procedimento as seguintes etapas: solicitei que citassem os produtos que tinham 1 litro, mediando-os com a ajuda de um medidor de 1 litro (garrafa). A água foi usada para representar o produto a ser medido. Depois fiz com que observassem outros mediclores que apontavam $1.000 \mathrm{ml}$ mas que tinham formatos diferentes. Questionei se a água caberia naquele outro medidor. A provocação serviu para levá-los à prática.

A maioria foi transferindo a água entre os diferentes medidores e percebeu que:

l litro $=1.000 \mathrm{ml}$

$1 / 2$ litro $=500 \mathrm{ml}$

Ao serem indagados sobre quanto preciso para ter um litro de cada produto da primeira alividade, os alunos sentiram-se motivados e passaram a desenvolver estratégias que os levassem a responder a questão.

A maioria dos alunos escreveu ou desenhou os produtos listados na primeira atividade que tínham menos de um litro. Estes produtos estavam em mililitros, eles haviam percebido a equivalência:-1 litro $=1.000 \mathrm{ml}-$ e lístaram os produtos. Utilizaram para a resolução o cálculo mental, o cálculo sistematizado, a calculadora, os medidores. 


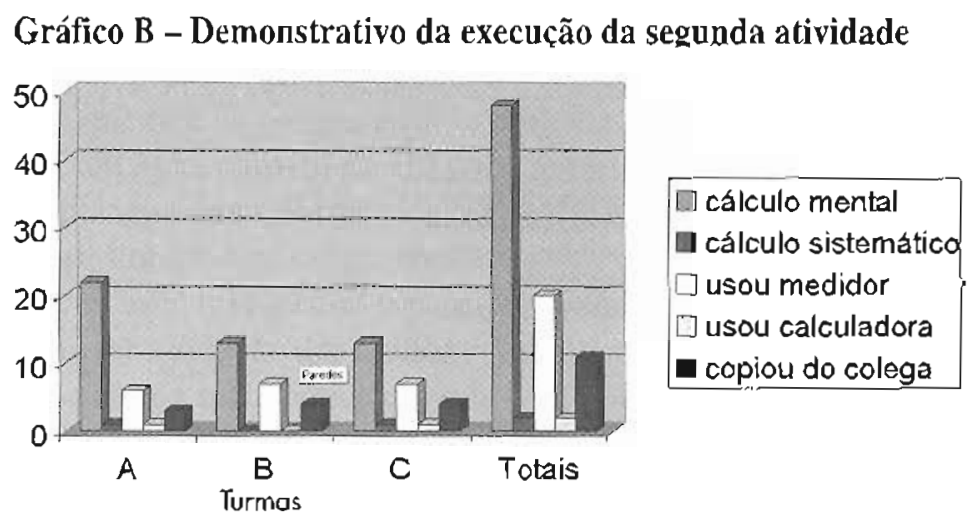

Na análise do desenvol vimento da segunda atividade percebi que alguns medidores não traziam as medidas corretas (mesmo os fornecidos pela escola); outros medidores não padronizados dificultaram a atividade; medidores de boca larga dificultaram a medição; a falta de domínio do sistema de numeração decimal dificultou o processo de compreensão e execução da atividade. Verifiquei que os alunos, que realizaram a atividade por cálculo mental ou por cálculo sistemático, tiveram maior número de acerto.

\section{Gráfico C - Demonstrativo dos resultados da segunda atividade}

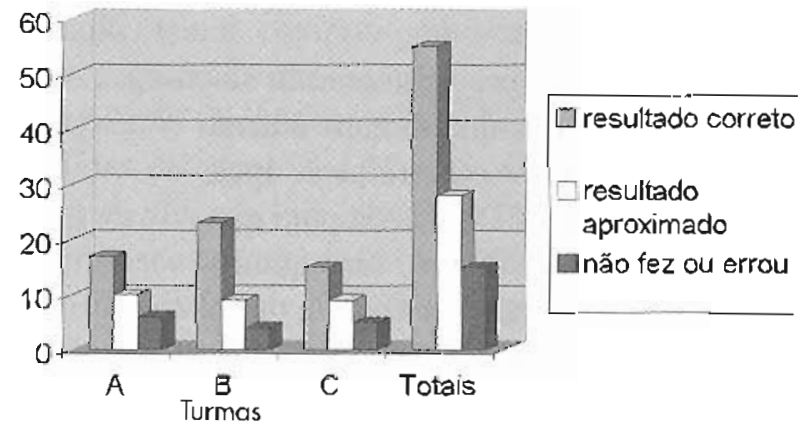

A terceira atividade teve como proposta a medição a partil da variação de medidores. O objelivo específico desta atividade foi fazer com que o aluno experimentasse diferentes medidores para obter uma mesma medida.

Orientamos os alunos a compararem os resultados obtidos sempre com medidores de 1 litro (com marcação de medidas). Depois provoquei-os, perguntando como usariam medidores de 1 litro, se nós fôssemos medir 2 litros.

Alguns alunos indicaram um pote de sorvete e justificaram a escoIha: "Na follhinha está marcado que tem 2 litros de sorvete". Então resol- 
vi desafiá-los, mostrando o pote de sorvete: "E vocês acreditam que aqui cabem 2 litros de sorvete?" Praticamente todos, ao olharem o pote de sorvete e a jarra de 1 litro, disseram que ali não caberiam 2 litros.

Juliclécio, 12 anos, comentou: "Enganaram a gente de novo, professora!"

Solicitei, então, que levantasse a mão quem acreditava que havia sido enganado. A maioria levantou a mão, justificando que não cabia porque a jarra e o pote tinham o mesmo tamanho. Como os alunos tinham utilizado várias vezes a jarra de 1 litro, afirmaram que essa era a capacidade dos dois medidores. Pedi a dois grupos de alunos, que achavam que no pote cabiam 2 litros, que provassem. Após várias tentativas viraram duas jarras de 1 litro e encheram o pote. No pote de sorvete, perto da borda tem um desnível. Um grupo encheu pouco acima do desnível, o outro exatamente no desnível. Perguntei em qual dos dois havia realmente 2 litros. Medimos novamente e a medida acima do desnível estava correta.

Sugeri que procurassem outras maneiras para medir dois litros: "Mostre quatro maneiras diferentes para medirmos 2 litros, utilizando estes três medidores:
a) medidor de 1 litro
b) medidor de $1 / 2$ litro
c) medidor de $240 \mathrm{ml}$ "mamadeira"

Durante a execução desse exercício a maioria dos alunos preferiu medir para resolver o problema proposto. Tanto os alunos que mediram quanto os que calcularam, não encontraram dificuldade para obter 2 litros utilizando os medidores (a) e (b). Em relação ao medidor (c), mamadeira, apesar de ele apontar até a medida $240 \mathrm{ml}$, ele podia conter $250 \mathrm{ml}$, isto acabou induzindo muitas crianças ao erro ou a resultados aproximados. Muitas crianças tentaram obter 2 litros utilizando o medidor (c) e o pote de sorvete de 2 litros, mas este não demarcava exatamente 2 litros, resultando em medidas aproximadas. Apenas alguns alunos que utilizaram cálculo sistemático, com ou sem calculadora, conseguiram chegar ao resultado exato. 


\section{Gráfico D - Demonstrativo da execução da terceira atividade}

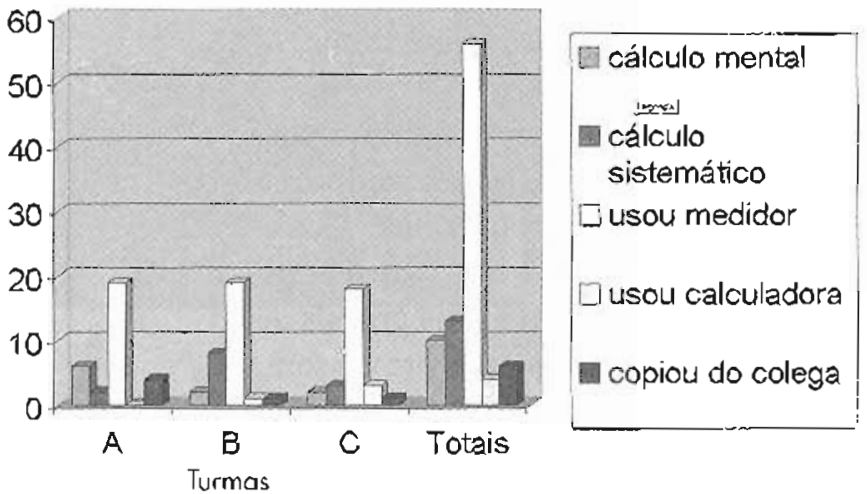

Havia três medidores para demonstrar quatro maneiras diferentes de se obter 2 litros. A solução para encontrar a quarta maneira era utilizar dois ou três medidores, mas os alunos encontraram soluções variadas e quando utilizavam o medidor (c) âlcançavam o resultado aproximado.

\section{Gráfico E - Demonstrativo dos resultados da terceira atividade}

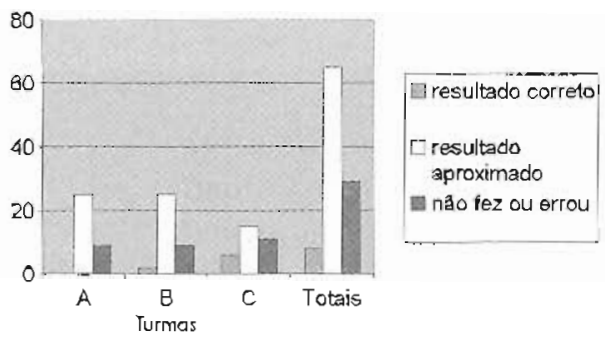

Na quarta atividade, denominada como comprar?, tivemos como objetivo especílico levar o aluno a praticar o raciocínio de multiplicação enquanto razão; fazer com que o aluno perceba a relação entre preço e quantidade ao comprar um produto.

Utilizamos como procedimento de orientação que voltassem a utilizar o folheto de supermercado, procurando saber quanto gastariam ao comprar 8 litros de sorvete.

Na resolução do problema a maioria percebeu o raciocínio multiplicação enquanto razão, pelo cálculo multiplicativo ou soma de parcelas iguais. Muitos não perceberam que como cada pote de sorvete continha 2 litros, era necessário comprar quatro potes, e calcularam a compra de oito potes, como se cada pote tivesse a capacidade de I Jitro. 


\section{Gráfico F - Demonstrativo da quarta atividade}

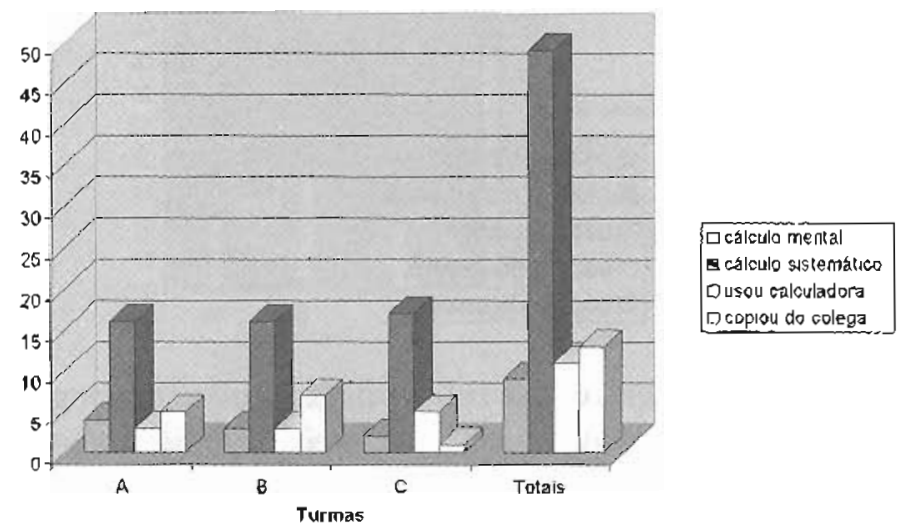

Nenhum aluno tentou descobrir através da divisão o preço de 1 litro de sorvete, para depois obter o preço de 8 litros. Alguns alunos perceberam que era necessária a compra de apenas quatro pores e conseguiram resolver o problema utilizando a multiplicação através da soma de parcelas, como o aluno Juliclécio, ou então utilizando a multiplicação sistemática, como o aluno Diego, 10 anos. Outros alunos, ao invés de calcularem a compra de 8 litros, calcularam a compra de oito poles, sem perceberem que estavam calculando a compra de 16 litros de sorvete.

\section{Gráfico $\mathrm{G}$ - Demonstrativo dos resultadlos da quarta atividade}

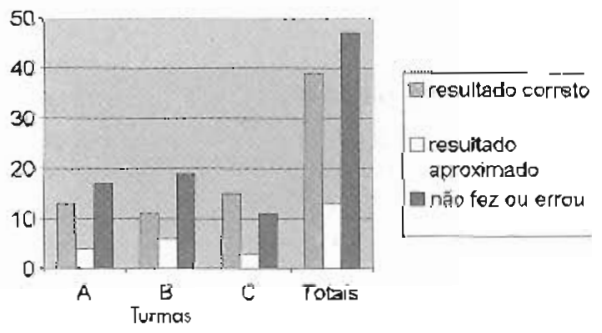

A festa do sorvele foi o mote da quinta atividade, que teve como objetivos específicos levar o aluno a associar e relacionar litro com seus submúltiplos mais usados e trabalhar o conceito de divisão. Para tanto, utilizanos as seguinles estratégias: pedi que imaginassem uma festa do sorvete em que cada participante teria direito a uma bola de sorvete de igual medida. Questionei se cada bola de sorvete fosse de $25 \mathrm{ml}$ (este número foi uma variável, mas percebi que era uma quantia muito pequena de sorvete, então nas tormas posteriores aumentei o tamanho da bola para $100 \mathrm{ml}$ ), quantas pessoas tomariam sorvete com um pole? 


\section{Gráfico H - Demonstrativo da execuçāo da quinta atividade}

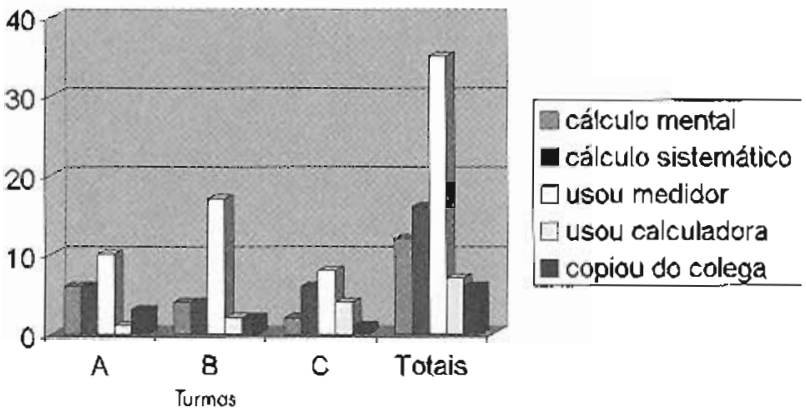

Os alunos perceberam que medidores de boca larga dificultam a medição, pois em um medidor de boca estreita é mais fácil perceber quando se acrescenta $25 \mathrm{ml}$, induzindo a resultados aproximados. $\mathrm{O}$ aluno Ednaldo, 14 anos, resolveu o problema com a calculadora, depois disse que tinha de medir para confirmar sua resposta.

Alunos das outras turmas que tinham que resolver o problema, considerando a bola de sorvete como $100 \mathrm{ml}$, resolveram-no com mais facilidade, medindo ou fazendo cálculo mental.

\section{Gráfico I - Demonstrativo dos resultados da quinta atividade}

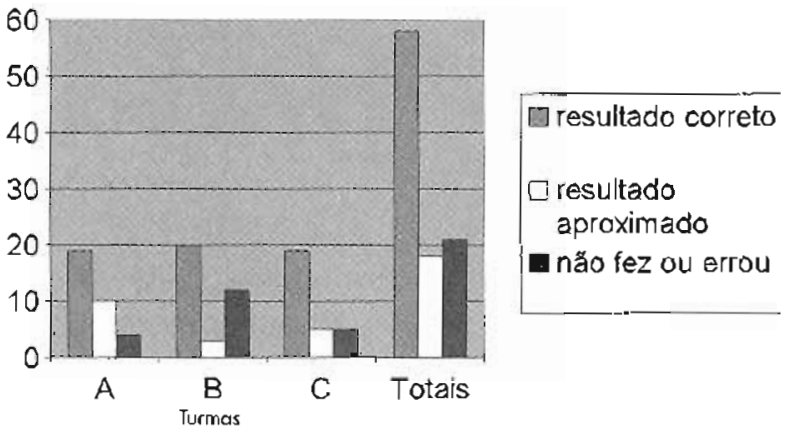

A sexta atividade teve como objetivo encher um recipiente de 20 litros. O objetivo foi o de testar o entendimento dos alunos sobre o assunto estudado com quantidades maiores. Adotamos como procedimento mostrar um recipiente de 20 litros vazio e perguntar se sabiam qual quantidade de água cabia naquele recipiente. Alguns alunos responderam que cabiam 20 litros e que sabiam disso por terem lido no próprio recipiente. Sugeri então a nova atividade, perguntando quantos copos de $200 \mathrm{ml}$ é preciso para encher este recipiente de 20 litros. 


\section{Gráfico J - Demonstrativo da execução da sexta atividade}

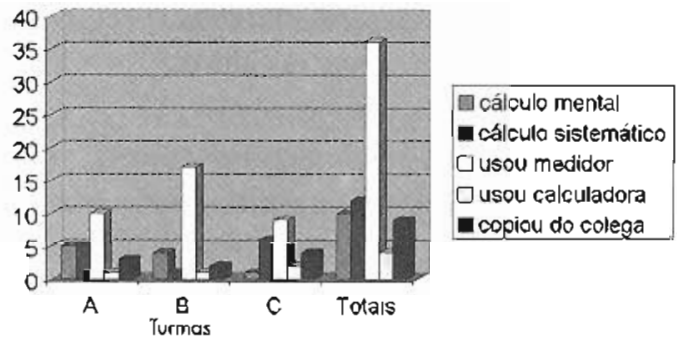

Alguns alunos utilizararn-se do cálculo sistemático, como Karina. Alunos que mediram copo por copo chegaram a números aproximados devido à quantidade irregular de água colocada em cada copo e se perderem na conta ao colocar uma quantidade relativamente grande de copos no recipiente.

A maioria dos alunos chegou ao resultado percebendo que em 1 litro tem cinco copos de $200 \mathrm{ml}$ e, a partir daí, mediam ou calculavam de cinco em cínco copos.

Milton tem problemas de relacionamento com as outras duas professoras, que reclamam por ele não fazer nada em suas aulas e perturbar os colegas. Porém, ele foi o primeiro a acabar todas as atividades de sua classe, todas por cálculo mental, e soube expressar o raciocínio utilizado para resolver o problema.

\section{Gráfico L - Demonstrativo dos resultados da sexta atividade}

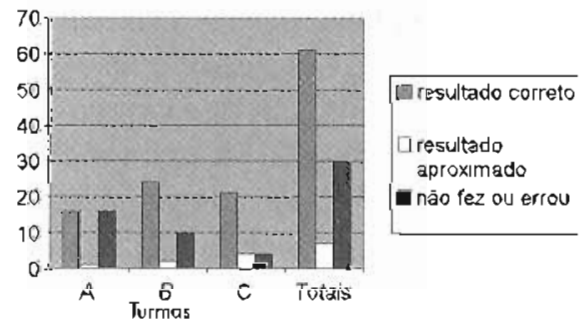

A última atividade teve como proposta que cada aluno fizesse seu próprio medidor. Essa atividade teve como objetivo concluir a experiência sobre medidas de capacidade. Perguntei aos alunos como eles fariam as marcas dos medidores. Um aluno respondeu: com régua; outro riu e afirmou: régua não mede água. Apareceram outras sugestōes como: fazer riscos e ir colocando o número etc. Então, o aluno Vanderlei disse: "Professora, é só a gente pegar outro medidor que tenha a marca certa, medir $100 \mathrm{ml}$, e passar para o nosso vidro. Aí a gente marca no nosso vidro uma risquinha". Todos acataram a idéia de Vanderlei. 
Separei os alunos em grupos, em cada grupo havia um pote de sorvete com água e um vidro de tinta. Solicitei que um integrante de cada grupo escolhesse um medidor padrão para seu grupo realizar a atividade. Cadá aluno tinha um vidro e um palito de dente para escrever no vidro.

Esta experiência ainda está em andamento. Nas próximas atividades trabalharemos medidas de peso, de forma semelhante ao que foi tratado no tema medidas de capacidade. As atividades vão surgindo a partir da necessidade e do interesse dos alunos. Após a experiência com medidas de peso, faremos bolo na sala de aula, para que utilizem e pratiquem as medidas de capacidade e peso.

Faremos também uma pesquisa sobre os preços dos ingredientes que utilizaremos para fazer o bolo, dividiremos o bolo e as clespesas, levantaremos suposições de quanto poderíamos lucrar vendendo o bolo etc.

Os alunos que anteriornnente se mostravam agressivos, bagunceiros e desinteressados, tiveram mudança positiva de comportamento durante e depois da experiência. Todos os alumos presentes participaram das atividades. Executaram todas as propostas de forma interessada e ordenada. Muitos alunos que antes não se respeitavam, conseguiram trabalhar em grupo, dividir o material, esperar a sua vez de fazer a experiência.

\section{RIESULTADOS ANIMADORES}

Gráficos M e N - Demonstrativos da defasagem idade/série
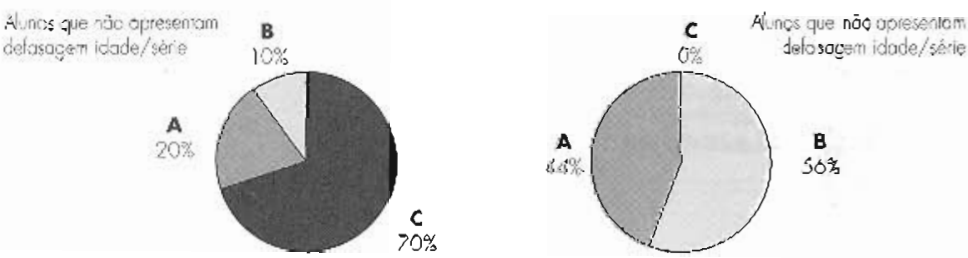

A quarta série $\mathrm{C}$, que não tem aluno com defasagem idade/série, lê melhor e escreve melhor do que as outras duas turmas. Antes da experiência também não apresentavam relevantes problemas de comportamento e já tinham bom aproveitamento em todas as disciplinas. Os alunos da quarta série A e da quarta série B, que lêm alto índice de defasagem idade/série, tinham, antes da experiência, aproveitamento baixo em todas as disciplinas. Agora, mesmo com leitura e escrita deficientes, estas duas turmas se saíram tão bem quanto a quarta série $\mathrm{C}$.

Apesar de todas as diferenças demonstradas nos gráficos acima, as três turmas se saíram muito bem nas atividades. 
Este trabalho foi uma experiência em conjunto, realizada pelos alunos e por mim, na qual cada atividade ia surgindo gradativamente de acordo com as dúvidas e necessidades que os alunos iam apresentando.

Ao relatá-la, pude perceber sua grandeza, pois avaliando os resultados de forma comparativa entre as turmas, os alunos e as atividades anteriores e atuais, notei que mesmo os alunos mais apáticos ou os mais desinteressados participaram. Os alunos indisciplinados e bagunceiros trabalharam de forma conjunta e, principalmente, os alunos analfabetos tentaram, através de desenho, por meio de medições, achar alguma resposta, muitas vezes errada, mas ao menos saíram da passividade e foram buscá-la.

Falando em aluno analfabeto, não posso deixar de citar a atuação do aluno Atos, que merece um registro à parte. Ele é um aluno muito esperto, brincalhão, contador de piadas, criador de histórias e interessado em notícias atuais do dia-a-dia, mas seu caderno sempre está incompleto. Chega a passar semanas sem completar uma frase escrita. Lê apenas com o auxílio de figuras e quando escreve não faz a correspondência entre escrita e fala, registra a palavra usando qualquer letra.

Desde que mudei a metodologia, tornou-se um dos alunos mais participativos, ficando aflito quando não resolve alguma atividade de Matemática. Ele surpreendeu pelo seu desempenho, realizando todas as atividades inicialmente por cálculo mental. Muitas vezes media para certificar-se da resposta e justificava oralmente cada uma. Para dar a resposta aos problemas por ele resolvidos corretamente, perguntava aos colegas como se escreviam as palavras, às vezes letra por letra, até conseguir passar para o papel a sua conclusão.

Agora, Atos que não escrevia nada, além de escrever o próprio nome, participa das aulas de todas as professoras, principalmente da aula de Português, pois pretende conseguir ler e escrever sem o auxílio dos colegas para, então, responder sozinho os problemas de Matemática.

Não desconsiderando a atuação dos outros 97 alunos, penso que pelo progresso obtido pelo aluno Atos todo meu trabalho valeu a pena. Ele é meu copo de água mineral. Descobri que esta é a melhor forma de trabalhar, nunca havia me sentido tão próxima dos meus alunos. 
Resumo: Professora de Matemática do ensino fundamental relata sua experiência de trabalho pedagógico desenvolvida com alunos da quarta série, em escola pública da Grande São Paulo. A partir de um folheto de supermercado, que anuncia produtos, quantidades e preços, a professora introduz conceitos de Matemática, como o de unidade padrão de medida, tacilitando o aprendizado dos alunos. A professora descobre que, ao aproximar a Matemática escolar da matemática da vida do aluno, consegue levá-los a uma atuação mais crítica e participativa no procedimento das informações transmitidas na escola.

Palavras-chave: Matemática, cotidiano, alunos, defasagem, ensino fundamental
Abstract: An elementary school Math teacher reports on her teaching experience developed with fourth grade students in a São Paulo public school. Based on a supermarket flier that announces products, quantities and prices, the teacher introduces Math concepts such as the standard measurement unit, making it easier for the students to learn. The teacher discovers that by approaching school math to the math there is $n$ the student's life, she is able to lead them to a more critical and participative role in processing information transmitted in school.

Key words: Mathematics, daily life, students, school out of pace, fundamental teaching 